\title{
Les Barthes, Labastide-du-Temple, Lizac
}

\section{Florent Hautefeuille}

\section{OpenEdition \\ Journals}

Édition électronique

URL : http://journals.openedition.org/adlfi/10842

ISSN : 2114-0502

Éditeur

Ministère de la culture

\section{Référence électronique}

Florent Hautefeuille, "Les Barthes, Labastide-du-Temple, Lizac », ADLFI. Archéologie de la France Informations [En ligne], Midi-Pyrénées, mis en ligne le 01 mars 1997, consulté le 22 avril 2019. URL http://journals.openedition.org/adlfi/10842

Ce document a été généré automatiquement le 22 avril 2019

(c) Ministère de la Culture et de la Communication, CNRS 


\title{
Les Barthes, Labastide-du-Temple, Lizac
}

\author{
Florent Hautefeuille
}

Date de l'opération : 1991 (PR)

Inventeur(s) : Hautefeuille Florent

1 La prospection diachronique entreprise sur les trois communes avait pour but de déterminer l'importance de l'occupation humaine mais aussi d'envisager la restitution du couvert végétal au travers d'une esquisse d'archéologie du paysage. La zone couverte, plus de 3000 ha, s'insère dans un contexte géographique qui se situe autour de deux méandres du Tarn, entre sa confluence avec la Garonne et celle, plus en amont, avec l'Aveyron.

2 Peu d'indices préhistoriques ont été recueillis et il ne s'agit tout au plus que de pièces isolées d'époque acheuléenne, moustérienne et néolithique provenant d'une zone de plateaux au nord de Lizac. L'absence d'indices du Paléolithique supérieur mais aussi de la Protohistoire ancienne et récente étant due, en grande partie, à de forts alluvionnements. Plusieurs sites gallo-romains ont été repérés à Lizac, mais également sur la commune des Barthes où un site se trouve à proximité immédiate de l'église. À Labastide-du-Temple, quatre gisements déjà connus ont pu être confirmés par prospection (Gallia, 1978, $2: 429$ ), alors que quatre autres sites sont inédits et parmi lesquels deux marquent les environs immédiats des églises Notre-Dame et Saint-Martin.

4 Une motte castrale arasée vers 1830 a pu être retrouvée aux Argigals (LesBarthes). Elle est mentionnée dès 1085 et disparaît de la documentation après 1122. La formation des villages de Lizac et des Barthes n'a pu être appréhendée car ils ont été entièrement détruits en 1930 par une inondation. Seules des données d'archives ont permis de signaler la présence à Lizac d'une église, aujourd'hui disparue, dédiée à saint Étienne, signalée par une bulle pontificale de 1096 et peut-être localisée (présence d'ossements humains et débris de construction) à l'ouest du village, au niveau du lieu-dit Le Gleyage. Une pêcherie 
est encore citée aux Barthes en 1097 alors que le village parait être formé en liaison avec la motte des Argigals toute proche. Le village de Labastide-du-Temple provient, en revanche, de l'extension du territoire des Templiers implantés à Lavilledieu-du-Temple depuis le milieu du XII ${ }^{e} s$. et qui s'est développé autour d'une commanderie établie au cours de la première moitié du XII ${ }^{e} s$. Une étude géomorphologique et géologique du lit majeur du Tarn a été entreprise afin de définir les zones favorables à l'implantation humaine. Basée sur des documents cartographiques et photographiques, elle a mis en évidence les secteurs topographiques les plus élevés dans le lit majeur et une zone de stabilité où le déplacement mineur a été peu important.

INDEX

Index chronologique : Antiquité romaine, Moyen Âge, Néolithique, Paléolithique moyen operation Prospection (PR)

Index géographique : Midi-Pyrénées, Tarn-et-Garonne (82), Barthes, Labastide-du-Temple, Lizac peuple Acheuléen, Moustérien 